\title{
Metastatic Carcinoma in the Uterine Cervix
}

National Cancer Institute

\section{Source}

National Cancer Institute. Metastatic Carcinoma in the Uterine Cervix. NCI Thesaurus.

Code C6334.

A carcinoma that has spread to the cervix from another anatomic site. 